\title{
Management of the pregnant inflammatory bowel disease patient on antitumour necrosis factor therapy: State of the art and future directions
}

\author{
Yvette PY Leung MD FRCPC ${ }^{1}$, Remo Panaccione MD FRCPC ${ }^{1}$, \\ Subrata Ghosh MBBS MD FRCPC FRCPE ${ }^{1}$, Cynthia H Seow MBBS MSc FRACP1,2
}

\begin{abstract}
YPY Leung, R Panaccione, S Ghosh, CH Seow. Management of the pregnant inflammatory bowel disease patient on antitumour necrosis factor therapy: State of the art and future directions. Can J Gastroenterol Hepatol 2014;28(9):505-509.
\end{abstract}

Antitumour necrosis factor (anti-TNF) therapy has been a major advance in the treatment of inflammatory bowel disease (IBD) by improving rates of mucosal healing, steroid-free remission, and decreasing rates of hospitalization and surgery. Because IBD affects women in their reproductive years, clinicians have and will continue to be asked in the future about the safety profile of these agents and their potential impact on pregnancy, the developing fetus and newborn. Immunoglobulin $\mathrm{G}$ transfer from the mother to fetus begins in the second trimester, with an elevation starting at 22 weeks of gestation and the largest amount transferred in the third trimester. Although research investigating the long-term outcomes of children exposed to anti-TNF therapy in utero is limited, there is no known adverse effect on either pregnancy or newborn outcomes including infectious complications with this class of drugs. The World Congress of Gastroenterology consensus statement on biological therapy for IBD considered infliximab and adalimumab to be low risk and compatible with use during conception and during pregnancy in at least the first two trimesters. Based on a clinical algorithm used at the University of Calgary Pregnancy and IBD clinic (Calgary, Alberta), recommendations have been provided on the management of pregnant patients on anti-TNF therapy, particularly with regard to thirdtrimester dosing, taking into account disease characteristics of individual patients. When educated about the safety of anti-TNF therapy during pregnancy, patients often choose to continue on therapy during the third trimester.

Key Words: Antitumour necrosis factor therapy; Inflammatory bowel disease; Pregnancy

The impact of antitumour necrosis factor (anti-TNF) therapy in the 1 treatment of inflammatory bowel disease (IBD) has changed our concept of disease remission from that of purely symptomatic remission to endoscopic healing, with a corresponding reduction in hospitalizations and surgeries for IBD. In Canada, the available anti-TNF agents for Crohn disease and ulcerative colitis are infliximab (IFX; Remicade, Janssen, USA), a chimeric immunoglobulin (Ig) G1 monoclonal antibody and adalimumab (ADA; Humira, Abbvie, USA), a recombinant human IgG1 monoclonal antibody; and, for ulcerative colitis, golimumab (Simponi, Janssen, USA), a recombinant human IgG1 monoclonal antibody. With the exception of certolizumab (not available in Canada), all Food and Drug Administration (FDA)-approved antiTNF agents for IBD are IgG1 antibodies with an Fc portion (IFX, ADA and golimumab).

Because IBD affects women in their reproductive years, clinicians have and will continue to be asked in the future about the safety profile of these agents and their potential impact on the developing fetus and newborn. While experiments involving nonhuman primates

\section{La prise en charge de la patiente enceinte atteinte d'une maladie inflammatoire de l'intestin traitée par un inhibiteur du facteur de nécrose tumorale : mesures de pointe et futures orientations}

L'inhibiteur du facteur de nécrose tumorale (anti-TNF) est un progrès important dans le traitement des maladies inflammatoires de l'intestin (MII), car il améliore le taux de guérison des muqueuses et de rémission sans stéroïdes et réduit le taux d'hospitalisations et d'opérations. Puisque les MII touchent des femmes en âge de procréer, les cliniciens doivent connaître le profil d'innocuité de ce traitement et ses répercussions possibles sur la grossesse, le fotus et le nouveau-né. Le transfert d'immunoglobuline $G$ de la mère au foetus s'amorce au deuxième trimestre, l'élévation commençant à 22 semaines de grossesse et le transfert le plus important s'observant au troisième trimestre. Même si les recherches sur les effets à long terme du traitement anti-TNF in utero chez les enfants qui y sont exposés sont limitées, cette catégorie de médicaments ne s'associe à aucun effet indésirable connu sur la grossesse ou le nouveau-né, y compris les complications infectieuses. D'après la déclaration consensuelle du Congrès mondial de gastroentérologie sur le traitement biologique des MII, l'infliximab et l'adalimumab sont peu à risque et peuvent être utilisés pendant la période périconceptionnelle et au moins les deux premiers trimestres de la grossesse. Selon un algorithme clinique utilisé à la clinique de grossesse et de MII de l'université de Calgary, en Alberta, des recommandations ont été formulées sur la prise en charge des patientes enceintes sous traitement anti-TNF, notamment la posologie au troisième trimestre, compte tenu des caractéristiques de la maladie de chaque patiente. Lorsqu'elles sont informées de l'innocuité du traitement anti-TNF pendant la grossesse, les patientes choisissent souvent de le poursuivre au troisième trimestre.

suggest that TNF- $\alpha$ is not required for normal development of the immune system (1), there are limited data regarding the long-term impact of these drugs on children beyond the first year of life. Both IFX and ADA are FDA category B drugs, meaning there is no evidence of risk in humans. However, due to concerns of the potential implications of TNF blockade in the fetus' developing immune system, uncertainty from both patients and physicians exist on how to best manage patients undergoing anti-TNF therapy during pregnancy.

According to the World Congress of Gastroenterology on biological therapy for IBD, IFX and ADA are considered to be low risk and compatible with use during conception and during pregnancy in at least the first two trimesters (2). However, the second trimester of pregnancy ends at gestational week 27 . With a full-term pregnancy duration spanning approximately 40 weeks, this poses a clinical dilemma for gastroenterologists and patients. Withholding an antiTNF agent for the entire third trimester equates to a significant drug holiday, and has risks for disease flare and the development of antidrug antibodies.

${ }^{1}$ Department of Medicine; ${ }^{2}$ Department of Community Health Sciences, University of Calgary, Calgary, Alberta

Correspondence: Dr Yvette Leung, Department of Medicine, University of Calgary, 3280 Hospital Drive Northwest, Calgary, Alberta T2N 4N1.

Telephone 403-592-5025, e-mail yvette.leung@albertahealthservices.ca

Received for publication March 12, 2014. Accepted July 1, 2014 


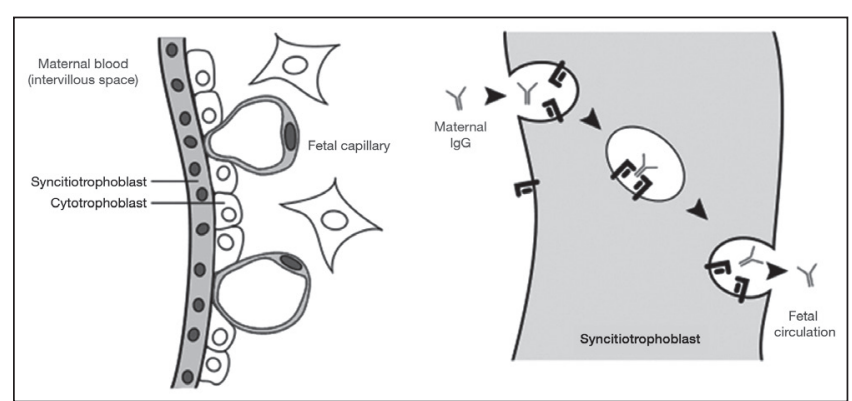

Figure 1) Active transplacental transport of immunoglobulin $G$ ( $(g G)$. Reproduced with permission, Oxford University Press (http://creativecommons.org/licenses/by-nc/2.5), Hazes JMW. Rheumatoid Am J Reprod Immunol 2011;50(11):1955-68

The present review focuses on the latest research investigating transplacental passage of anti-TNF agents, the safety data on antiTNF therapy during pregnancy, the optimal use of anti-TNF agents during pregnancy and highlight future areas requiring research.

\section{HOW DO IGs CROSS THE PLACENTA IN A NORMAL PREGNANCY?}

$\mathrm{IgG}$ is the only antibody class that significantly crosses the human placenta and, by doing so, provides short-term passive immunity to the newborn. This crossing is mediated by the neonatal $F_{c}$ receptor $\left(F_{c} R n\right)$ that is expressed on syncytiotrophoblast cells of the placenta (3). Syncytiotrophoblasts on the maternal side of the placenta internalize $\mathrm{IgG}$ in endosomes (Figure 1). FcRn is expressed on the internal surface of endosomes. The endosomes then fuse with the fetal side of the syncytiotrophoblast, where the IgG dissociates from the FcRn to the fetal circulation (4). Preferential transport occurs for IgG1, followed by $\operatorname{IgG} 4$, then $\operatorname{IgG} 3$, with $\operatorname{IgG} 2$ having the lowest affinity for binding. IgG transfer from the mother to fetus begins in the second trimester, with an elevation starting at 22 weeks' gestation, with the largest amount transferred in the third trimester (Figure 2) (4-6). Accordingly, there are significantly lower levels of IgG and corresponding seroprotection to diphtheria, tetanus, pertussis, Haemophilus influenza type b and Neisseria meningitides serogroup C in preterm compared with full-term infants (7).

\section{PLACENTAL TRANSFER OF ANTI-TNF AGENTS}

Placental transfer of IFX was first published as a case report in 2006 (8). An infant born to a mother receiving IFX $10 \mathrm{mg} / \mathrm{kg}$ with the last infusion two weeks before delivery was found to have higher than expected levels at six weeks of age. Because IFX was not detected in the breast milk, this case provided the first evidence in humans of transplacental transfer of an anti-TNF agent. The authors of this case report and subsequent reviews and guidelines suggested terminating IFX at gestational week $30(9,10)$. Zelinkova et al (11) then tested this guideline by determining the IFX levels in cord blood at delivery and the mothers' peripheral blood at delivery in four patients. All four patients received IFX between gestational weeks 21 and 30. Of the four infants, three had IFX levels in cord blood that were two- to threefold higher than in the peripheral blood of their mothers (mothers received IFX at gestational weeks 26, 26 and 30). The patient who received IFX at gestational week 21 gave birth to a newborn with no detectable IFX in the cord blood.

Mahadevan et al (12) studied maternal peripheral blood, and newborn cord and peripheral blood of 11 IFX-treated patients and 10 ADAtreated patients. The median time from the last dose of IFX to delivery was 35 days (range two to 91 days). In every case, the cord or infant level of IFX was higher than the mother's at the time of delivery, and took two to seven months to become undetectable. The median cord drug level was $160 \%$ of the maternal drug level (range $87 \%$ to $400 \%$ ). The median time from the last dose of ADA to delivery was 5.5 weeks

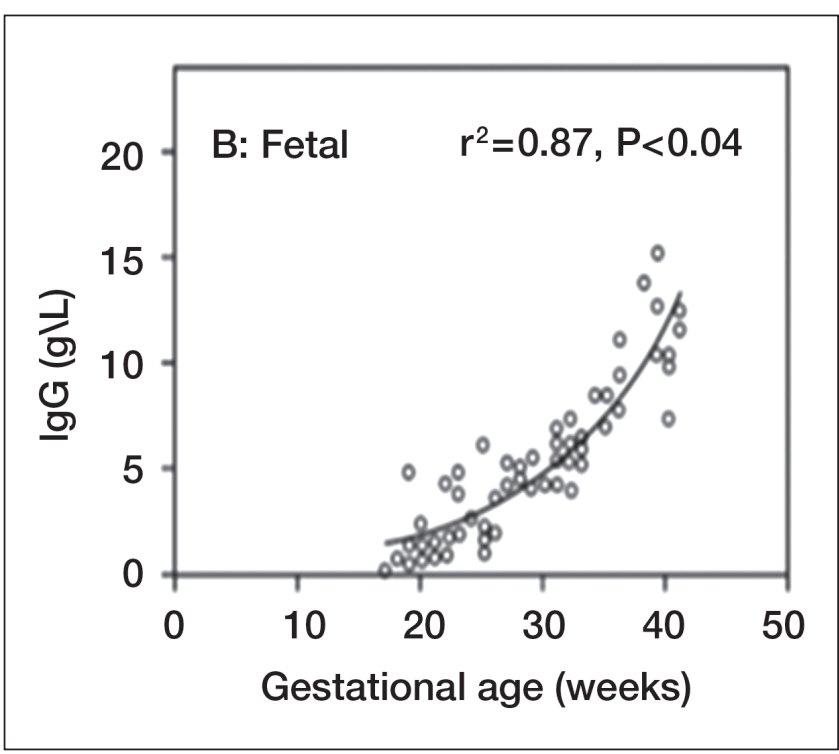

Figure 2) Immunoglobulin $G$ ( $I g G)$ placental transport over time. Reproduced with permission, Wiley-Blackwell Publishing Ltd, Malek A. Evolution of maternofetal transport of immunoglobulins during human pregnancy. Am J Reprod Immunol 1996;36:248-55

(range 0.14 to 8 weeks). Again, in every case, the cord or infant level of ADA was higher than the mother's at the time of delivery, with the median cord drug level 179\% of the maternal drug level (range $98 \%$ to $293 \%)$. Levels in newborns were detectable for at least 11 weeks from birth. There were no significant complications to newborns during the follow-up period in both IFX and ADA groups.

Zelinkova et al (13) further published on 31 pregnancies in 28 women with IBD: 17 IFX-treated patients and 11 ADA-treated patients. In 12 of 17 IFX-treated patients, and all 11 ADA-treated patients, antiTNF therapy was intentionally discontinued during pregnancy before week 30 (range, gestational weeks 18 to 27). In the IFX group, they compared the cord blood of the newborn between the group that had $\leq 10$ weeks compared with $>10$ weeks (the group that discontinued) from the last infusion to delivery. In the early discontinuation group the drug was stopped on average at week 23 . The mean cord blood concentration of IFX was significantly lower in the early discontinuation group (13). The study was not powered to detect clinical differences in newborn outcomes and, presently, there are no published data regarding the effects of early versus late discontinuation of anti-TNF therapy on the neonatal immune system. The authors of the study recommended discontinuation of the anti-TNF agent in the second trimester, although this has been met with some controversy.

\section{WHAT HAPPENS WHEN PATIENTS DISCONTINUE ANTI-TNF THERAPY DURING PREGNANCY?}

In the same study published by Zelinkova et al (13), data regarding discontinuation of anti-TNF therapy during pregnancy demonstrated the risk for disease relapse. In the ADA group, therapy was discontinued between gestational weeks 21 and 26 in 11 patients. Two patients relapsed: one flared at gestational week 30 and required corticosteroids; the second flared at gestational week 36 and underwent an elective Caesarean section at week 37. In the IFX group, of 12 patients with early discontinuation of the therapy, one developed an allergic reaction postpartum on resumption of IFX. In total, this patient had a drug holiday of 22 weeks because of postpartum concerns about mastitis. In Leuven (Belgium), of patients taken off antiTNF by week 22 of pregnancy, $12.5 \%$ of patients flared in the third trimester and $20.6 \%$ flared postpartum (14). In the series published by Mahadevan et al (12), 60\% of patients flared when ADA was stopped $>35$ days before delivery. 
More importantly, there are no prospective controlled data to demonstrate that corticosteroid use is safer for maternal and neonatal outcomes in the third trimester than anti-TNF therapy. Reddy et al (15) published a case control study demonstrating that pregnant women with IBD requiring hospitalization for active disease were at significant risk for preterm delivery compared with pregnant IBD patients with stable disease (mean 35.0 weeks versus 38.7 weeks; $\mathrm{P}<0.05$ ) and were also at risk for delivering a low birthweight infant (mean $2001 \mathrm{~g}$ versus $3018 \mathrm{~g} ; \mathrm{P}<0.05)$ (15). This highlights the importance of stringent disease control during pregnancy.

\section{SAFETY OF ANTI-TNF AGENTS DURING PREGNANCY}

Although there is evidence that newborns exposed to anti-TNF therapy during gestation are born with higher levels of IFX and ADA than the mother, there are no data that these agents are associated with short-term adverse newborn outcomes. To put risks into perspective, in the general Canadian population, the rate of congenital anomalies is $6.0 \%$, preterm birth is $7.7 \%$ and Caesarean section is $27.1 \%(16)$.

The largest prospective registry of 1052 pregnant women with IBD is the Pregnancy and Neonatal Outcomes in Women with Inflammatory Bowel Disease (PIANO) registry. In an abstract presented at Digestive Diseases Week in 2012, 797 patients had completed their pregnancy with no reported increase in congenital anomalies by drug exposure (17). Of these patients, 337 were unexposed to a biologic or a thiopurine, 265 were thiopurine exposed, 102 were biologic (IFX, ADA or certolizumab) exposed, and 59 exposed to combination biologic and thiopurine therapy. The proportion of congenital anomalies overall was $4.6 \%$. There was no increase in preterm birth, intrauterine growth retardation, Caesarean section or neonatal intensive care unit associated with drug exposure.

Gisbert and Chaparro (18) systematically reviewed data from 21 studies involving 462 women with IBD exposed to anti-TNF agents during pregnancy and also concluded that these therapies are low risk in the short term. The overall proportion of spontaneous abortions (11\%) and congenital anomalies (1.7\%) were similar to the control groups. There was no increase in rates of preterm birth, intrauterine growth retardation or Caesarean section associated with drug exposure. Nielsen et al (19) published a similar systematic review, with the inclusion of 58 studies. Due to the heterogeneity of studies, results could not be metaanalyzed; however, there were four studies with a control population that reported nonsignificant ORs or relative risks for spontaneous abortion, preterm delivery, low birth weight and or congenital anomalies in patients exposed to anti-TNF therapy during pregnancy to those without anti-TNF drug exposure.

The infliximab safety database and the The Crohn's Therapy, Resource, Evaluation, and Assessment Tool Registry (TREAT) were also included in these two recent systematic reviews. The infliximab safety database is a retrospective registry maintained by the manufacturers of IFX and relies on voluntary reporting of pregnancies of women with rheumatoid arthritis (RA) or Crohn disease (20). There were 96 pregnancies that resulted in 100 births. Only two major structural anomalies were reported: one Tetralogy of Fallot and one intestinal malrotation with no differences from the observed outcomes to expected outcomes from the general population. The TREAT registry is an ongoing, prospective, observational, multicentre, long-term registry of North American patients with Crohn disease. In the TREAT registry, there were 142 IFX-exposed pregnancies with no differences in the rate of live births or congenital anomalies compared with IFX versus non-IFX-treated patients (21). A review of the FDA database of adverse events with etanercept (not used in IBD), IFX and ADA from 1999 to 2005 found a total of 61 congenital anomalies in 41 children born to mothers taking anti-TNF agents (22). Fifty-nine percent of the children had one or more congenital anomalies that were part of the VACTERL spectrum (vertebral abnormalities, anal atresia, cardiac defect, tracheoesophageal defects, renal defects, and limb defects). However, there was no denominator available for the calculation of incidence, and no child exhibited the full VACTERL syndrome, which requires a minimum of three of the seven defects to be present.

\section{SAFETY OF ANTI-TNF THERAPY IN LONG-TERM OUTCOMES OF EXPOSED CHILDREN}

Apart from data on congenital anomalies and data from PIANO on outcomes up to one year, there are little long-term data regarding outcomes of children exposed to anti-TNF therapy in utero. Bortlik et al (23) published outcomes on a series of 25 children with a median age of 34 months at the last follow-up (range 14 to 70 months) exposed to IFX or ADA. The mean gestational age of exposure to the anti-TNF agent was 26 weeks (range 17 to 37 weeks). There was one case of psychomotor delay in a boy born as a dizygotic twin and four cases of serious infections requiring hospitalization. While circulating levels of anti-TNF drug in the child were not measured, the infections occurred between 10 and 29 months of age when, according to existing pharmacokinetic data, the anti-TNF agent would likely have been cleared from the infant's circulation. There were no clinical signs of immunodeficiency or impaired cellular immunity. Mildly low levels of IgA and/or IgG were observed in seven of 17 infants. In the absence of a control group, the authors attributed the findings to transient hypogammaglobulinemia of infancy. In the same study, 15 infants exposed to IFX received the live Bacille Calmette-Guerin vaccine. Three of these children experienced local skin reactions. Despite the absence of systemic adverse effects in this study, there was a previous case report of disseminated Bacille Calmette-Guerin in an infant exposed to antiTNF therapy in utero after receiving the live vaccine (24). Therefore, we would strongly recommend avoidance of all live vaccines in children who have had in utero exposure to anti-TNF therapy until at least six months of age.

Both the infliximab safety database (20) and the study by Carter et al (22) included patients with RA. The British Society for Rheumatology Biologics Register reported on 130 pregnancies to women with RA exposed to anti-TNF therapy during conception and or/pregnancy (25). In the subgroup of patients exposed to anti-TNF monotherapy, the rate of spontaneous abortion was $25 \%$ compared with $10 \%$ in the neverexposed group; however, the cohort was small and results were only presented descriptively. Reports of anti-TNF exposure in patients with psoriasis have been limited to case reports/series $(26,27)$.

\section{HOW DO WE MANAGE PATIENTS ON ANTI-TNF AGENTS DURING PREGNANCY?}

At the University of Calgary (Calgary, Alberta), patients are seen preconception to discuss the benefits and potential risks of continuing therapy during pregnancy up to and including the third trimester. The decision to continue or stop a treatment during pregnancy represents a very difficult decision for gastroenterologists and patients. Given the known half-lives of IFX ( 9.5 days) and ADA (10 to 20 days) and the incremental rise in transplacental transfer of immunoglobulins after gestational week 22, we aim to minimize anti-TNF exposure in the final one-half of the third trimester because the results of studies investigating the long-term outcomes of children exposed to anti-TNF therapy in utero are lacking. At this time, there are insufficient data to support complete anti-TNF therapy cessation in the third trimester for the reasons outlined above, namely increased risk for disease flare. Therefore, our approach is to minimize both disease flare and neonatal exposure by modifying the timing of the last dose of anti-TNF therapy, giving it earlier in the third trimester where possible. This decision needs to be individualized, taking into consideration the disease characteristics of the patient (Figure 3).

The decision to stop anti-TNF treatment partway through pregnancy only applies to patients in stable, steroid-free remission with objective markers to confirm remission

The priority for any patient is induction and maintenance of steroidfree remission, regardless of pregnancy status. Due to the risk of flare with cessation of anti-TNF therapy, we also recommend that an 


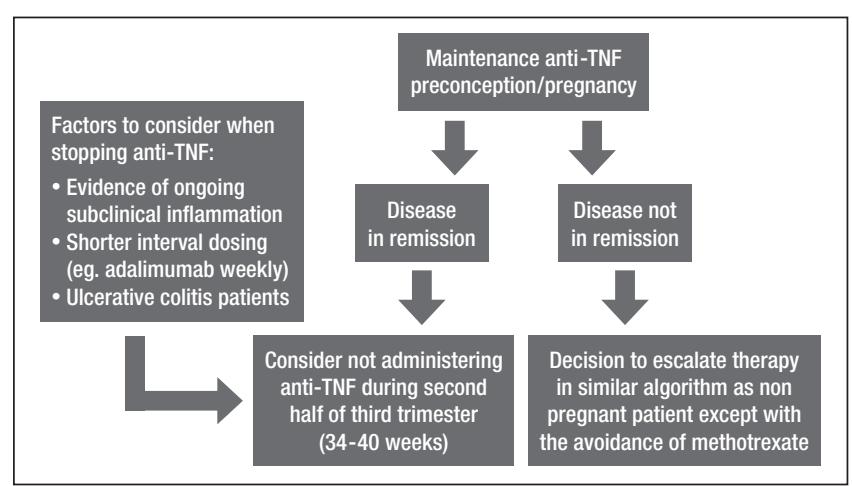

Figure 3) Algorithm for management of patients on maintenance antitumour necrosis factor (anti-TNF) therapy

objective measure of activity should be performed to confirm that the disease is in deep remission such as small bowel ultrasound, flexible sigmoidoscopy or fecal calprotectin.

Patients in steroid-free clinical remission who may be at risk for flare if there is a missed dose should continue therapy

Patients who are at risk for flare if there is a missed dose include individuals who feel clinically well, but are not in deep remission based on imaging (for example, patients at risk of ileal obstruction) or who have elevated biomarker levels such as fecal calprotectin.

Other factors to consider include the current dosing interval. For example, if a patient is on weekly ADA, withholding a dose in early third trimester would equate to eight to 10 missed doses, increasing the risk for flare. Finally, there is evidence that patients with ulcerative colitis are at higher risk for disease flare during pregnancy; therefore, missing multiple doses in this disease phenotype may increase their risk for flare (28).

\section{Patients initiating anti-TNF therapy during pregnancy require special consideration}

Patients initiating anti-TNF therapy while pregnant are very different from patients who enter pregnancy already on maintenance therapy. Depending on the disease severity at presentation and response to steroids, patients who are diagnosed with IBD during pregnancy may require initiation of anti-TNF therapy. Even in patients with known IBD, there is still a risk for disease flare during pregnancy (28) that may require initiation of anti-TNF therapy. Induction dosing of antiTNF therapy depends on the stage of pregnancy (Figure 4). In patients who are at gestational week $<22$, anti-TNF therapy can be prescribed at standard induction-dose intervals similar to nonpregnant patients. Subsequent maintenance dosing should not be withheld in the third trimester. For patients who require anti-TNF therapy after 22 weeks' gestation, the decision to initiate anti-TNF will depend on the patient's disease activity and phenotype (similar to how nonpregnant patients are managed) with the added consideration of time to delivery. For example, in patients who are likely to imminently deliver, anti-TNF therapy can likely be delayed until after pregnancy. We recommend that all patients with a new diagnosis of IBD during pregnancy are comanaged with specialists from the high-risk obstetrics group and internists from the maternal fetal medicine group.

Patients with a well-documented history of stable remission confirmed by objective markers, on anti-TNF therapy, may discontinue therapy earlier during the pregnancy to reduce transplacental transfer of drug to the fetus

In our clinic, patients are informed that transplacental passage of antiTNF agents begins in early second trimester, with the largest amount transferred in the third trimester. Discontinuing therapy at the start of the third trimester can represent a significant drug holiday for IFX and ADA patients, and often it is the patients themselves who are hesitant to stop the drug this early given concerns of disease flare and its impact on

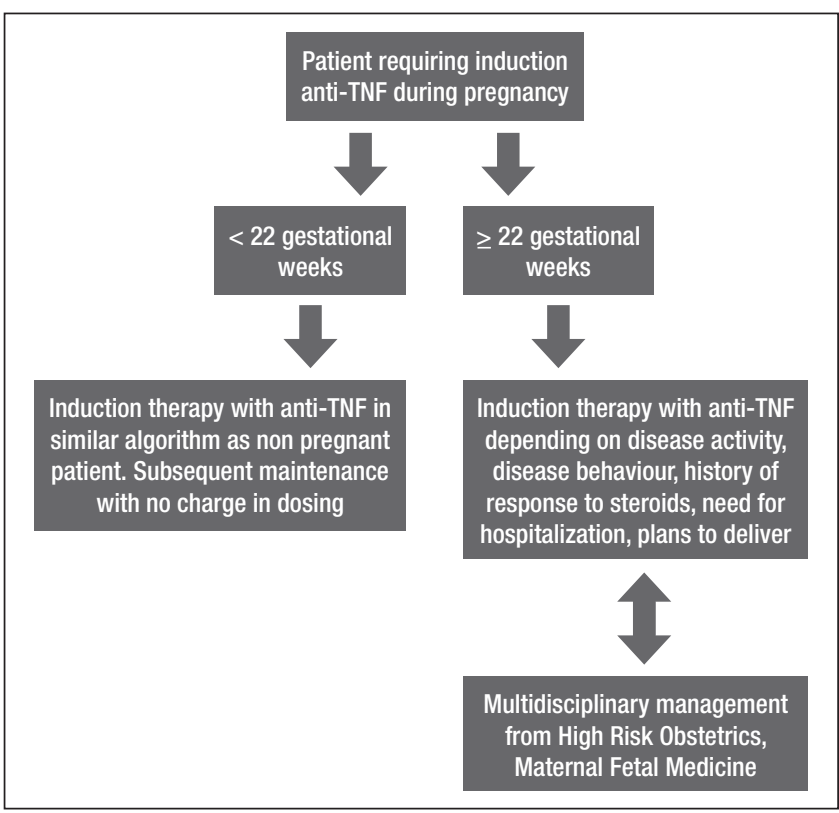

Figure 4) Algorithm for management of patients who need antitumour necrosis factor (anti-TNF) induction during pregnancy and subsequent maintenance

both mother and child. Ongoing and open dialogue between physician and patient is fundamental and, when presented with the data, the majority of our patients choose to accept anti-TNF therapy during early third trimester. The majority of our patients on eight-weekly dosing for IFX and bi-weekly dosing of ADA receive their last dose of anti-TNF therapy at gestational week 32 for IFX and gestational week 34 for ADA.

Monotherapy or combination therapy in pregnancy and issues of immunogenicity

Studies investigating anti-TNF levels and antidrug antibody levels during pregnancy are not available at this time. Immunogenicity or the presence of antidrug antibodies are associated with adverse reactions and reduced efficacy of therapy $(29,30)$. Therefore, in our practice, we do not routinely discontinue thiopurines that are used in combination with anti-TNF therapy if the patient was on the thiopurine during preconception. In the case of a patient who wants to stop concomitant thiopurine therapy, we discuss the benefits and risks of monotherapy and combination therapy. Additionally, we discuss the extensive data on the safety of thiopurines in pregnancy $(31-33)$. However, due to its FDA rating of $\mathrm{D}$, despite education of its excellent safety profile during pregnancy, many patients are inclined to stop this class of drugs during pregnancy when used as a concomitant immunomodulator. For patients who are initiating anti-TNF therapy during pregnancy, we tend not to start thiopurines for the first time during pregnancy (as the concomitant immunomodulator) due to the small but possible risk of thiopurine-associated pancreatitis and hepatitis, and side effects such as nausea and malaise.

Methotrexate is a well known teratogen in women and should be stopped a minimum of six months before conception.

\section{Role of therapeutic drug monitoring in pregnancy}

Presently, there are no data on anti-TNF therapy therapeutic drug monitoring in pregnancy to guide or optimize dosing. Therefore, we recommend that clinicians use the same decision making in pregnant patients as they would in their nonpregnant patients.

\section{Unanswered questions}

1. What are the long-term effects on the immune system of children born to mothers on anti-TNF agents? If there are implications for the immune system of children, does this change depending on trimester exposure? 
2. Can anti-TNF therapeutic drug monitoring in the first trimester with subsequent modification of dose and dosing interval be used to optimize disease course for the remainder of the pregnancy and postpartum?

3. Can we individualize anti-TNF therapy based on an understanding of an individual's pharmacokinetics and, therefore, tailor dosing during pregnancy to minimize placental transfer? In other words, change the dose but not stop therapy.

\section{FUTURE DIRECTIONS}

With the introduction of new therapeutic molecules on the market for the treatment of IBD, the uptake of anti-TNF therapy and other biologics will likely continue to increase and, therefore, an increasing number of patients in their reproductive years will be on these agents. In response to the abovementioned clinical and research needs, a Maternofetal Outcomes Research in IBD - Canadian Registry (MORe CaRe) has been started with two fundamental goals. The first goal is to optimize the clinical care of pregnant IBD patients through education, continuing medical education of physicians (family physicians, obstetricians and fertility experts, and gastroenterologists), and establishment of clinical care pathways and guidelines that apply to Canadian practitioners. The second goal is to establish a national biorepository with biospecimens from mother's peripheral blood, breastmilk, cord blood and infant peripheral blood to answer additional questions regarding the long-term safety and optimal use of biologics in pregnancy.

\section{REFERENCES}

1. Arsenescu R, Arsenescu V, de Villiers WJ. TNF-alpha and the development of the neonatal immune system: Implications for inhibitor use in pregnancy. Am J Gastroenterol 2011;106:559-62.

2. Mahadevan U, Cucchiara S, Hyams JS, et al. The London position statement of the World Congress of Gastroenterology on Biological Therapy for IBD with the European Crohn's and Colitis Organisation: Pregnancy and pediatrics. Am J Gastroenterol 2011;106:214-23; quiz 24 .

3. Firan M, Bawdon R, Radu C, et al. The MHC class I-related receptor, $\mathrm{FcRn}$, plays an essential role in the maternofetal transfer of gamma-globulin in humans. Int Immunol 2001;13:993-1002.

4. Palmeira P, Quinello C, Silveira-Lessa AL, Zago CA, Carneiro-Sampaio M. IgG placental transfer in healthy and pathological pregnancies. Clin Developmental Immunol 2012;2012:985646

5. Saji F, Samejima Y, Kamiura S, Koyama M. Dynamics of immunoglobulins at the feto-maternal interface. Rev Reproduction 1999;4:81-9.

6. Malek A, Sager R, Kuhn P, Nicolaides KH, Schneider H. Evolution of maternofetal transport of immunoglobulins during human pregnancy. Am J Reproductive Immunol 1996;36:248-55.

7. van den Berg JP, Westerbeek EA, Berbers GA, van Gageldonk PG, van der Klis FR, van Elburg RM. Transplacental transport of IgG antibodies specific for pertussis, diphtheria, tetanus, Haemophilus influenzae type b, and Neisseria meningitidis serogroup C is lower in preterm compared with term infants. Pediatr Infect Dis J 2010;29:801-5.

8. Vasiliauskas EA, Church JA, Silverman N, Barry M, Targan SR, Dubinsky MC. Case report: Evidence for transplacental transfer of maternally administered infliximab to the newborn.

Clin Gastroenterol Hepatol 2006;4:1255-8.

9. Gisbert JP. Safety of immunomodulators and biologics for the treatment of inflammatory bowel disease during pregnancy and breast-feeding. Inflamm Bowel Dis 2010;16:881-95.

10. Van Assche G, Dignass A, Reinisch W, et al. The second European evidence-based consensus on the diagnosis and management of Crohn's disease: Special situations. J Crohn's Colitis. 2010;4:63-101.

11. Zelinkova Z, de Haar C, de Ridder L, et al. High intra-uterine exposure to infliximab following maternal anti-TNF treatment during pregnancy. Aliment Pharmacol Ther 2011;33:1053-8.

12. Mahadevan U, Wolf DC, Dubinsky M, et al. Placental transfer of anti-tumor necrosis factor agents in pregnant patients with inflammatory bowel disease. Clin Gastroenterol Hepatol 2013;11:286-92
13. Zelinkova Z, van der Ent C, Bruin KF, et al; Dutch Delta IBD Group. Effects of discontinuing anti-tumor necrosis factor therapy during pregnancy on the course of inflammatory bowel disease and neonatal exposure. Clin Gastroenterol Hepatol 2013;11:318-21.

14. Schnitzler F, Fidder H, Ferrante M, et al. Outcome of pregnancy in women with inflammatory bowel disease treated with antitumor necrosis factor therapy. Inflamm Bowel Dis 2011;17:1846-54.

15. Reddy D, Murphy SJ, Kane SV, Present DH, Kornbluth AA. Relapses of inflammatory bowel disease during pregnancy: In-hospital management and birth outcomes. Am J Gastroenterol 2008;103:1203-9.

16. Information CIfH. In due time, why maternal age matters 2011. $<$ https://secure.cihi.ca/free_products/AIB_InDueTime_ WhyMaternalAgeMatters_E.pdf> (Accessed February 17, 2014).

17. Mahadevan U, Martin C, Sandler RS, et al. PIANO: A 1000 patient prospective registry of pregnancy outcomes in women with IBD exposed to immunomodulators and biologic. Gastroenterology 2012;142:S-149. (Abst)

18. Gisbert JP, Chaparro M. Safety of anti-TNF agents during pregnancy and breastfeeding in women with inflammatory bowel disease. Am J Gastroenterol 2013;108:1426-38.

19. Nielsen OH, Loftus EV Jr, Jess T. Safety of TNF-alpha inhibitors during IBD pregnancy: A systematic review. BMC Med 2013;11:174.

20. Katz JA, Antoni C, Keenan GF, Smith DE, Jacobs SJ, Lichtenstein GR. Outcome of pregnancy in women receiving infliximab for the treatment of Crohn's disease and rheumatoid arthritis. Am J Gastroenterol 2004;99:2385-92.

21. Lichtenstein GR, Feagan BG, Cohen RD, et al. Serious infection and mortality in patients with Crohn's disease: More than 5 years of follow-up in the TREAT registry. Am J Gastroenterol 2012;107:1409-22.

22. Carter JD, Ladhani A, Ricca LR, Valeriano J, Vasey FB. A safety assessment of tumor necrosis factor antagonists during pregnancy: A review of the Food and Drug Administration database. J Rheumatol 2009;36:635-41.

23. Bortlik M, Duricova D, Machkova N, et al. Impact of anti-tumor necrosis factor alpha antibodies administered to pregnant women with inflammatory bowel disease on long-term outcome of exposed children. Inflamm Bowel Dis 2014;20:495-501.

24. Cheent K, Nolan J, Shariq S, Kiho L, Pal A, Arnold J. Case report: Fatal case of disseminated BCG infection in an infant born to a mother taking infliximab for Crohn's disease. J Crohn's Colitis 2010;4:603-5.

25. Verstappen SM, King Y, Watson KD, Symmons DP, Hyrich KL; BSRBR Control Centre Consortium. Anti-TNF therapies and pregnancy: Outcome of 130 pregnancies in the British Society for Rheumatology Biologics Register. Ann Rheumatic Dis 2011;70:823-6.

26. Puig L, Barco D, Alomar A. Treatment of psoriasis with anti-TNF drugs during pregnancy: Case report and review of the literature. Dermatology 2010;220:71-6.

27. Berthelot JM, De Bandt M, Goupille P, et al. Exposition to antiTNF drugs during pregnancy: Outcome of 15 cases and review of the literature. Joint Bone Spine 2009;76:28-34.

28. Pedersen N, Bortoli A, Duricova D, et al. The course of inflammatory bowel disease during pregnancy and postpartum: A prospective European ECCO-EpiCom Study of 209 pregnant women. Aliment Pharmacol Ther 2013;38:501-12.

29. Karmiris K, Paintaud G, Noman M, et al. Influence of trough serum levels and immunogenicity on long-term outcome of adalimumab therapy in Crohn's disease. Gastroenterology 2009;137:1628-40.

30. Baert F, Noman M, Vermeire S, et al. Influence of immunogenicity on the long-term efficacy of infliximab in Crohn's disease. N Engl J Med 2003;348:601-8.

31. de Meij TG, Jharap B, Kneepkens CM, van Bodegraven AA, de Boer NK; Dutch Initiative on Crohn and Colitis. Long-term follow-up of children exposed intrauterine to maternal thiopurine therapy during pregnancy in females with inflammatory bowel disease. Aliment Pharmacol Ther 2013;38:38-43.

32. Coelho J, Beaugerie L, Colombel JF, et al. Pregnancy outcome in patients with inflammatory bowel disease treated with thiopurines: Cohort from the CESAME Study. Gut 2011;60:198-203.

33. Casanova MJ, Chaparro M, Domenech E, et al. Safety of thiopurines and anti-TNF-alpha drugs during pregnancy in patients with inflammatory bowel disease. Am J Gastroenterol 2013;108:433-40. 


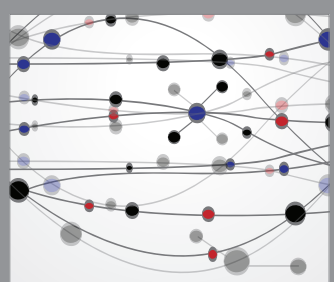

The Scientific World Journal
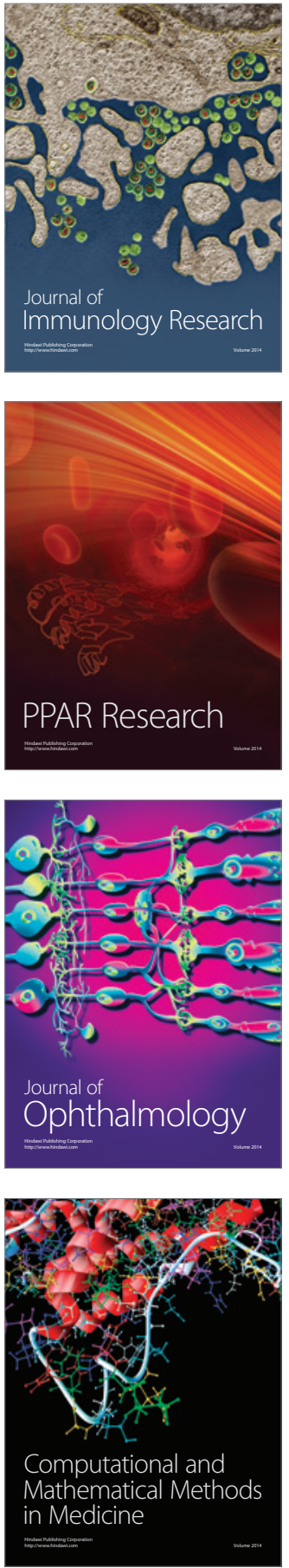

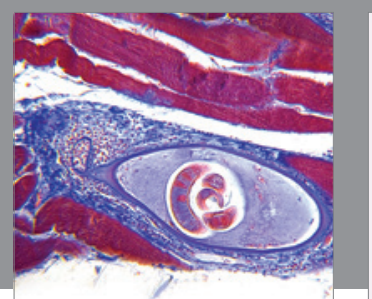

Gastroenterology Research and Practice

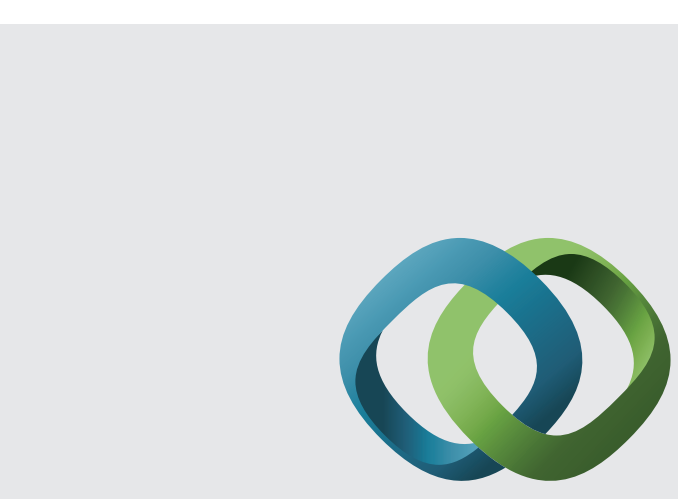

\section{Hindawi}

Submit your manuscripts at

http://www.hindawi.com
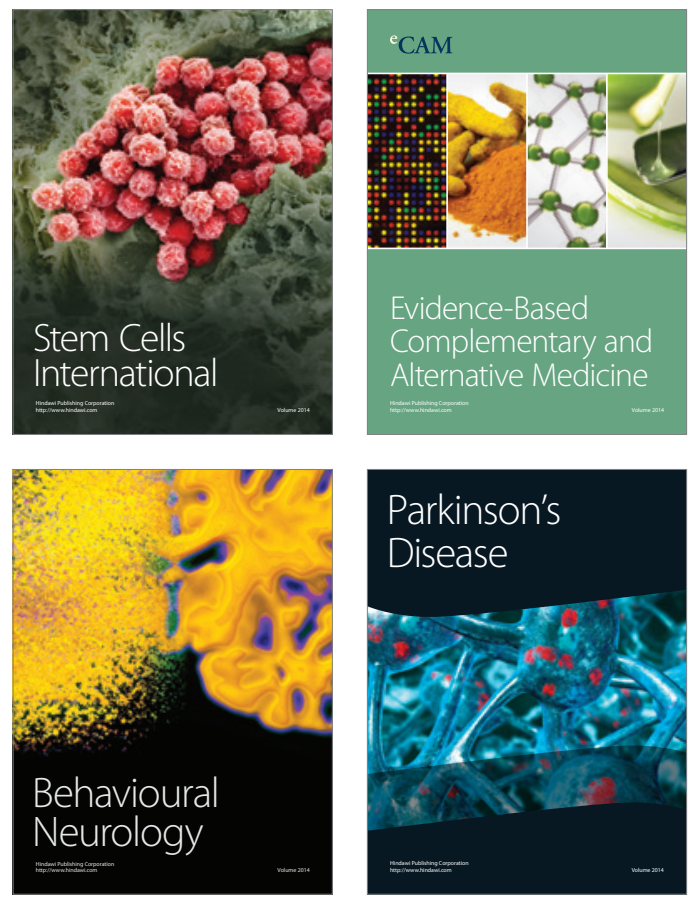
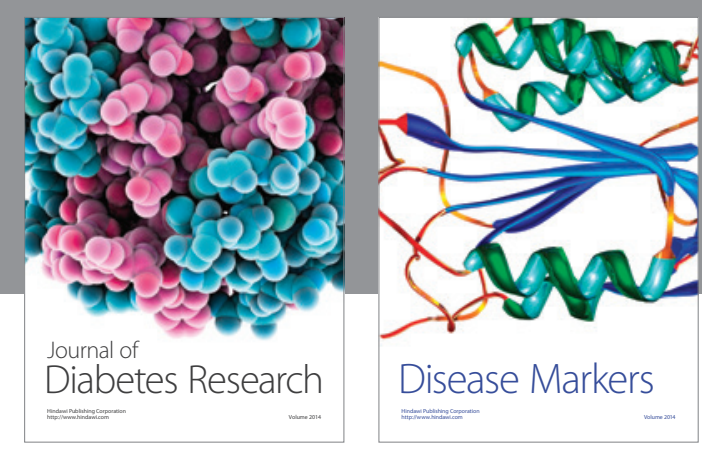

Disease Markers
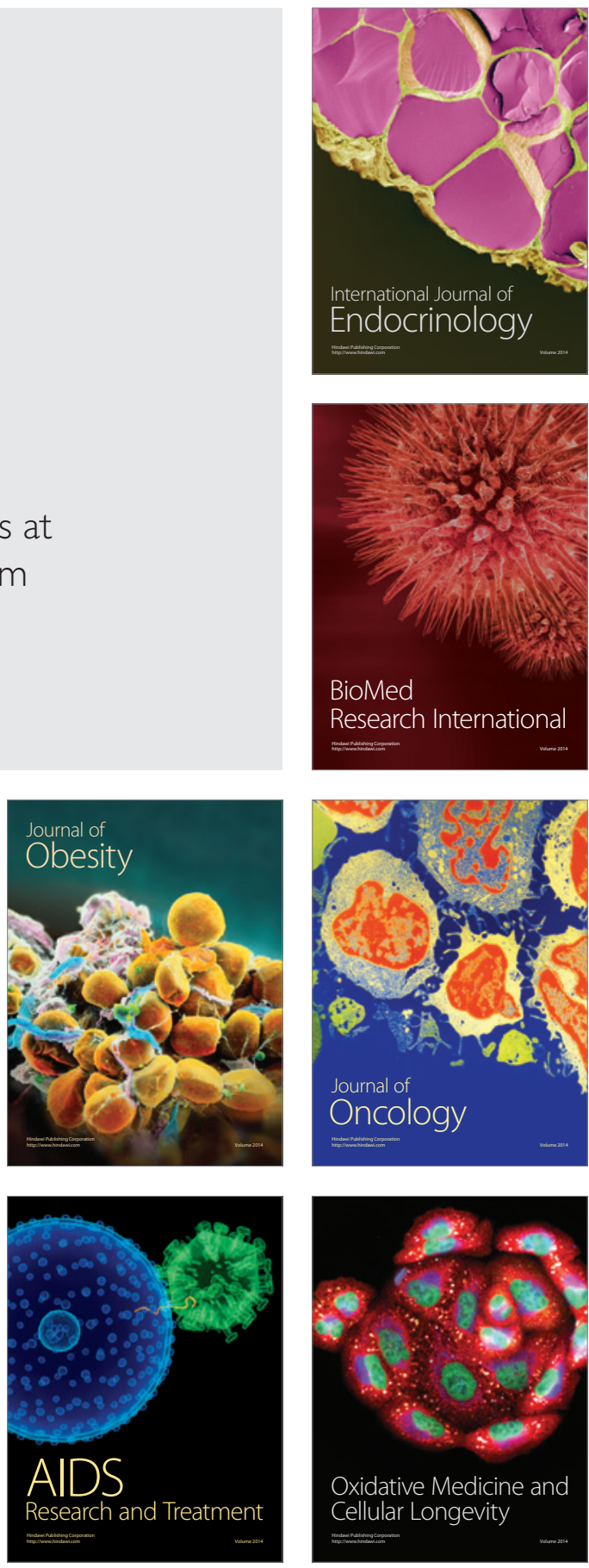